\title{
FEMUR BAŞI AVASKÜLER NEKROZU
}

\author{
Sinan Adıyaman*
}

\section{ÖZET}

Femur başı avasküler nekrozu kemik dokunun canlı elemanlarının idiopatik veya bir hastalığa sekonder olarak ölümü ile seyreden patolojik bir süreçtir. Hastalığı tedavi edebilmek nekrotik süreci engellemek güç olduğundan zordur. Tedavi seçenekleri hastalığın hangi evrede bulunduğuna göre farklılık gösterir.

Anahtar kelimeler: Avasküler Nekroz, Femur Başı.

\section{SUMMARY}

Avascular necrosis of the femaral head

Avascular necrosis of the femoral head occurs idiopathically or secondary to a number of conditions and is a pathologic process resulting from the death of Iiving elements of bone. It is difficult to treat this condition because of the lack of effective measures to interrupt the necrosis process. The consensus among several treatment options depends on the stage of the disorder at the time of diagnosis.

Key words: Avascular Necrosis, Femoral Head.

\section{Tanım ve Tarihçe:}

Kemiğin osteonekrozu veya avasküler nekrozu ilk olarak Munro tarafından $1738^{\prime}$ de tarif edilmiştir. Travma sonrası femur başında bir komplikasyon olarak izlenen majör deformite Cruveillier tarafından yayınlanmıştır. (1) 1930 yılında Phemister femur başı avasküler nekrozunun etyolojisi, patogenezi ve tedavisi konusunda ilk bilgilerimizin oluşmasını sağlamıştır. (2) Bu günkü bilgilerimiz ışığında femur başı avasküler nekrozu kemiğin canlı elemanlarının ortadan kalkması ile devam eden bir patolojik bir süreçtir. Bu süreç spesifik bir patolojiye ait olmayıp, mekanik ve biyolojik faktörlerin etkisi ile femur başı kan dolaşımının bozulmasıyla sonlanan çeşitli patolojilerin bir sonucudur. Osteonekroz genç hastaları etkileyebilir. ve bunun sonucunda sıklıkla bilateral patoloji ile sonlanabilir. Femur başı avasküler nekrozu 3 ila 5 yıl içerisinde çeşitli evrelerden geçerek kalçanın dejeneratif artritine sebep olur. Doğal seyri esnasında önceki evrelere gerileme olmaksızın progresyon gösterme eğilimindedir.

\section{Anatomi:}

Femur başının sirkülasyonu detaylı bir şekilde tarif edilmiştir. (3) Medial femoral sirkumfleks arter superior ve inferior retinaküler arter dallarını verir. Superior retinaküler arter superior metafizyal ve lateral epifizyal arter dallarına ayrılır. İnferior retinaküler dal ise inferior metafizyal damarlar olarak devamlılık gösterir. Obturator arter asetabular dalı üzerinden ligamentum teres arterini besler. Bu arter de medial epifizyal arter olarak sonlanır. Femur şaftı ve trokanterik bölgeden femur boynuna ulaşan arterler subkortikal pozisyonda boynun proksimal kısmında sonlanırlar. Lateral ve medial epifizyal arterler femur başının lateral $2 / 3$ ve medial $1 / 3$ kısmını, inferior metafizyal arter ise femur boynunu besler. Erişkinde çocuklardakine benzer olarak epifiz kanlanmasını andıran bir yapı olsa da dar çapta damarların beslediği inaktif yağ dokusu içeren sarı ilik hakimdir ve farklı olarak sinüzoidlerle karakterize metafizyel kırmızı ilik artık yoktur. Eklem kıkırdağının beslenmesi subkondral sirkülasyonun derin tabakası ve periferi aracılığı ile olur. Subkondral prekapil-

\footnotetext{
* Ankara Üniversitesi El Cerrahisi Bilim Dalı
} 
ler halka kemik iliğinden orijin alarak kanallardan geçer. Derin kıkırdak tabakada tek bir halkada sonlanır. Kemik iliğindeki postkapiller venüllere döner. Bu kanlanma kemik iliğinden farklıdır ve kondro-ossöz bilę̧ke için spesifiktir.

Kondro-ossöz bileşkenin kanlanması sadece anatomiye bağımlı değildir. Aynı zamanda sabit, etkili bir beslenmenin sağlanması için fonksiyonel dinamik bir sistem gereklidir. Bu sistem, kan akımı ve kemik basıncının etkilerine açıktır. Kemik içi basıncı, bazı bölgesel fonksiyonel otonomik faktörler ve indirek olarak sistemik kan basıncı ile orantılıdır. Kemik kan akımına etki eden faktörler kardiak output, kas kontraksiyonu ve intramedüller arteryel basınç gibi faktörlerden etkilenir. Örneğin sistemik basıncın düşmesi intramedüller basıncın azalmasına, femoral venlerin oklüzyonu ise venöz ve intramedüller basıncın artmasına neden olur. ( 4,5 )

\section{Etyoloji:}

Femur başı avasküler nekrozu oluşumunda birçok sebep sorumlu tutulmuşsa da, travma dışında hiçbir sebeple ilgili açıklama bu patolojik fenomenin oluşumunda rol oynayan biyolojik prosesi açıklamaya tam anlamıyla yetmemektedir. Etyolojide sıklıkla travma olusturan sebepler sorumlu tutulmaktadır. Travma ve diğer sebepler Tablo 1'de gösterilmiştir. Transservikal kırık, travmatik kalça çıkığı, femur başında kompresyon kırığı gibi travmalar, sıklıkla femur boynunda deplasmana neden olarak superior retinaküler ve lateral epifizyal arterleri yaralar. Sadece medial epifizyal arter ve ender olarak inferior metafizyal arter intakttır. Osteonekroz travma sonucu damarlardaki bu yaralanmayı müteakip 8 saat içerisinde ortaya çıkar. Radyolojik olarak izlenebilen ve mekanik faktörler sonucu ortaya çıkan segmenter kollaps ise 6 ay sonradır. (6) Kırık olmaksızın da travma sonrasında osteonekroz gelişebileceği bilinmektedir.(7) İatrojenik travma sonrasında da geç segmenter kollaps izlenebilir. Bu, sıklıkla trokanterik kırık sonrasında kalça plakları ile fiksasyonuna veya konjenital kalça displazilerinin veya epifiz kaymalarının kuvvetli manipülasyonuna sekonderdir. Ayrıca kapsül eksizyonu, sinoviektomi, koksa vara için yapılan cuneiform osteotomiler gibi cerrahi girişimler de osteonekroz riski taşırlar.

Femur başı avasküler nekrozunda travma dışında fizyopatolojisi çok iyi bilinmemekle beraber çeşitli hastalıklar ve ilaçlar kesin sorumlu tutulmaktadır. Steroid kullanımına bağlı osteonekroz için; yağlı bir karaciğerden yă̆ embolizasyonu, yağ nekrozu, steroid
Tablo 1. Femur başı avasküler nekrozu etyolojisi

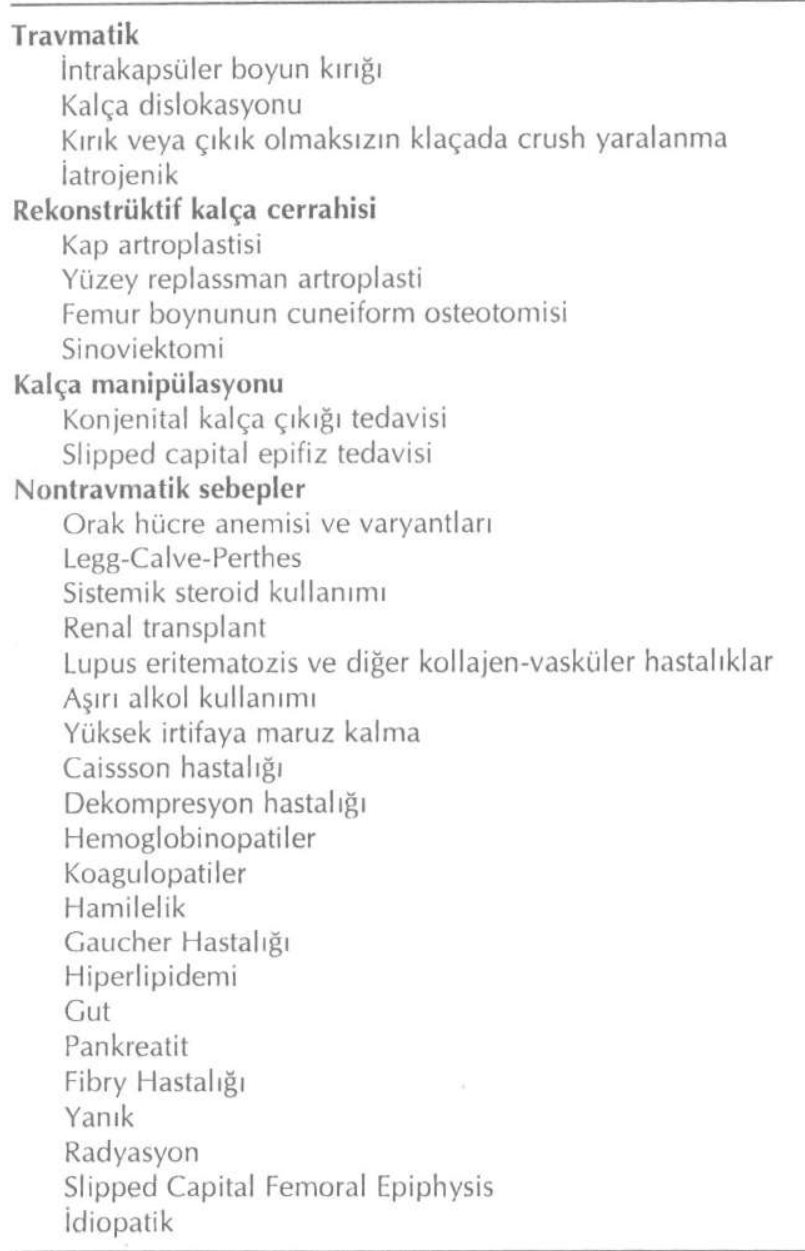

vasküliti, osteoporotik kemikte kompresyon kırı̆ı̆ ve artmış koagülasyon ve viskozitenin lokal damar lümenlerinde neden olabileceği tromboz.gibi açıklamalar getirilmiştir. Alkole bağlı osteonekroz için ise yă̆ embolisi sorumlu tutulmuştur. (6) Hemoglobinopatilerde ise femur başının yük taşıyan kısmındaki kan akmının mekanik bozukluğu söz konusudur. Benzeri etyolojiler esas alınarak yapılan incelemelerde esas rol oynayan faktörün proksimal femurda intraossöz basıncın artmassı olduğu anlaşılmıştır. Femur başında iskemik bir patolojiye neden olarak, venöz obstrüksiyon yaratan herhangi bir sebep kompartman sendromuna benzer şekilde intraossöz basıncı arttırmakta ve iskemik süreci hızlandırmaktadır.( 8 )

\section{Patogenez, Klinik ve Radyoloji:}

Klinik ve patolojik değişiklikler etyolojiyi takiben aylar ve hatta yıllar sonra ortaya çıkabilirken histolojik 
ve metabolik değişiklikler saatler içerisinde ortaya çıkar. Bu değişiklikleri osteonekrozun erken ve geç safhaları olarak inceleyebiliriz. Vasküler değişimi takiben 12 saat içerisinde hücreler canlılıklarını kaybederler. Ancak histolojik değişiklikler 48 saat ve radyolojik değişiklikler 2 ay sonra ortaya çıkar. Kemik trabeküllerinin ölümü 2 hatta 4 hafta sonradır. Eklem kıkırdağı ise sinovyal sıvıdan beslenmesi dolayısı ile patolojik değişimlerden uzaktır. Femur başı temelinde vasküler fibröz doku tamir sürecinin bir gereği olarak birinci haftadan itibaren ortaya çıkar. Bu esnada diffüz osteopeni dışında radyolojik bir anormallik gözlenmez. Klinik olarak ani ortaya çıkan tek taraflı ağrı dışında semptom yoktur. Hastalığın bu başlangıç safhasında eklem hareketleri korunmuştur.

Geç patolojik evrede ise tamir fibröz dokunun ilerlemesi ile sona ermiştir. Bu dokunun sert duvarları avaskülerdir. Geniş segmenter kollaps mekanik olarak kompresyon altında kalmış kemikte artmıs dansiteye yol açar. Bu esnada onarım sürecinin de devam etmekte olduğu bölgelerden kaynaklanan radyolusensi izlenebilir. Femur başının superior ve subkondral kısmında radyolusen bir hat izlenebilir. Bunun sebebi eklem kıkırdağının alıındaki ayrılmış olan kansellöz hücrelerin ölümü ile oluşan kollapstır. Bu, sferik bir yüzeye sahip bir femur başından düzleşmiş ve distorsiyone olmuş bir femur başına geçiş sürecidir. Yük taşıyan eklem yüzeyinde düzleşme, yama tarzında radyolusen gösteren bölgelerle karakterize bir radyolojik görünüm ile beraberdir. Asetabulum ve eklem kıkırdağı ise hastalığın çok ileri evrelerine kadar korunmuştur. Bu lokalizasyonda ortaya çıkan skleroz, kistik dejenerasyon ve osteofit formasyonu, çok ileri evrelerde dejeneratif artrit oluşma fazında görülür. Artık bu evrede kalça ağrısı ileri derecededir ve kalça hareketleri bozulmuştur. Hastalığın başlangıcında tek taraflı olan patoloji, hastaların \%55'inde 2 yıl içerisinde karşı tarafı da tutar. (9)

\section{Sinıflama:}

Femoral başın tutulum derecesinin ortaya konulabilmesi, en uygun tedavi şeklinin belirlenmesi açısından önem taşır. Bu nedenle çeşitli yazarlar tarafından hastalığın hangi evrede olduğunun belirlenebilmesi amacı ile çeşitli sınıflamalar ortaya atılmıştır. $(10,11)$

Bu sınıflamalarda MR değişiklikleri ve kemik sintigrafisi yardımı ile hastalığın erken veya ileri evrede oluşuna ve başın tutulum derecesine göre tedavi planlaması yapılabilmektedir. Klinik seyir, ağrı ve hareket kısıtlılığı tedaviyi ve prognozu belirleyici olabilirken, ortaya atılmış evrelemelerde hesaba katılmamıştır. Nekrozun genişliği klinik seyir üzerinde etkilidir. Tablo 2'de klinik uygulamalarımızda sıkça kullandığımız Ficat sınıflaması gösterilmiştir.

Tablo 2. Ficat'ın femur başı osteonekrozu için önerdiği radyolojik evreleme

\begin{tabular}{ll}
\hline Evre & Kriter \\
\hline I & Normal röntgen, MR görünüm, kemik sintigrafisi \\
IIA & Diffüz poroz, skleroz veya kistik değişim \\
IIB & Düzleşme veya "crescent" belirtisi \\
III & Başın konturlarında bozulma \\
IV & Eklem aralığında daralma, düzleşmiş kontur, ba- \\
& şın kollapsı \\
\hline
\end{tabular}

Teşhis:

Hastalığın erken evrelerinde teşhis konulması femur başında meydana gelebilecek kollapsı önlemek açısından önemlidir. İyi bir anamnez ve kalçaların detaylı bir klinik muayenesi, özellikle kalça hareketlerinin iyi bir dökümantasyonu çok yol göstericidir. Fizik muayene bulgularının konvansiyonel ve MR gibi modern görüntüleme yöntemleri ile korelasyonu erken teşhise olanak sağlar. Üzerinde durduğumuz vasküler değişikliklerin erken radyolojik bulguları kontrol grafileri ile beraber değerlendirildiğinde, erken teşhis ve sonuçta kalçanın segmenter kollapsının önlenebilmesi için gerekli tedavi planlaması mümkün olabilir. Evrelendirme için de kullanılan kemik sintigrafisi duyarI bir tanı aracı olsa da spesifik değildir. Bu amaçla en yaralı tanı aracı sinyal değişiklikleri gösteren MR görüntülemedir. Günümüzde intraossöz basınç ölçümü, venografi, $(5,12)$, tetrasiklin floresans (13), termal dilüsyon, arteriografi gibi yöntemler yerini MRG yöntemine bırakmıştır. Belirlenmiş risk faktörleri olması durumunda, MR ve kemik sintigrafisi karşılaştırma amacı ile karşı kalçayı da içerecek şekilde olmalıdır.

\section{Tedavi:}

Femur başı osteonekrozu tedavisi güç bir problemdir. Tedavi esnasında hastalığın hangi evrede bulunduğu kadar, önceden belirtildiği üzere etyoloji, semptomların süresi, ağrı, yaş, genel durum, hastalığın unilateral ve bilateral oluşu da belirleyicidir.

En ideal yaklaşım femur başı replasmanından önce anatomik yapının korunmasının sağlanmasıdır. Canlılığını kaybetmiş dokunun genişliği tedaviyi yönlendirir. Tutulan segment yük taşıyan bölgeye yakın değil 
ise, bu durumda nekrotik kısmın vital kemik ile yer değiştirilme şansı yüksektir.

Yük taşıyan bölgede artmış kuvvet segmenter kollapsın progresyonuna neden olabilir. Cerrahi olmayan tedavi prensipleri femur başı tutulumunun minimal olduğu durumlarda geçerlidir. Ağrının kontrolü gibi cerrahi dışındaki yaklaşımlar, ancak teşhiste şüphe olduğu ve takipte rekonstrüksiyon gerektirmeyecek evrelerde, progresyonun olmadığı durumlarda söz konusudur. Birçok yazar evre I ve II'deki hastaların takipte progresyonu olduğunu ve özellikle evre III lezyonları olan hastaların teşhis sonrası \%68 oranında artroplastiye gereksinim duyduğunu ortaya koymuşlardır. (9, $14,15)$ Özellikle evre III lezyonu olan hastalarda cerrahi dışındaki tedavi yöntemleri hiçbir fayda sağlayamamaktadır. (16) Bu nedenle esas tedavi prensibi olan erken teşhis ve femur başının korunması progresyon riski olan hastalarda cerrahi alternatifleri öncelikli düşündürmektedir. Segmenter kollapsın oluşumunu önlemek amaçlı patolojik süreci değiştirecek cerrahi tedavi alternatifleri tartışmalıdır.

'Core dekompresyon' trokanter majör üzerinden direk lateral insizyon ile distal kısımdan boyuna doğru drilleme uygulamasıdır. Bu cerrahi teknik ile nekrotik alanın biyopsisi yapılır ve radyolojik kontrol altında subkondral yüzeye dek nekrotik alan temizlenir ve kanlanma sağlanır. Bu yöntemin genç hastalarda tek başına uygulanması sonrası elde edilen sonuçların takiplerde cerrahi dışı yöntemlere göre çok da avantajlı olmadığı gösterilmiştir. Genel kanı progresyonun önlenemediği, ancak genç hastalarda artroplastiye gidişin geciktirilebildiğidir. $(16,17)$ Bu nedenle bu yönteme ek olarak; otojen veya allogreft kansellöz kemik, osteokondral greft, kas-pediküllü kemik greftleri, serbest vaskülarize iliak ve fibula greftleri ile klinikte sıklıkla kullandığımız ve olumlu sonuçlarını gözlemlediğimiz pediküllü iliak krest uygulanabilir. (18) Drilleme sonrasında eklem yüzeyine mekanik destek amaçlı greft uygulaması tek başına potansiyel kollaps riskini ortadan kaldıramamaktadır.(19)

Nekrotik alanın küretajını müteakip kansellöz kemik ile defektin doldurulması özellikle kollaps sonrası kötü neticeler vermektedir. Bu nedenle bazı yazarlar kas-pediküllü kemik greftini posteriordaki pencereye yerleştirmekte ve taze kadavra osteokondral greftleri kullanmaktadırlar. $(18,20)$

Rutin klinik uygulamamız olan vaskülarize iliak kemik grefti nekrotik alanın eksizyonu sonrası subkondral alanda canlı kemik dokusu sağladığı gibi, ek bir kanlanma artışı ve osteoprogenitor hücreler ile os- teoindüksiyon için büyüme faktörlerinin ortama gelmesini de sağlar. (21) Evre II ve III lezyonları olan genç olguların 'core dekompresyon' ve kemik greftleme ile tedavisinin üstünlüğü bu günkü bilgilerimize göre tartışmasızdır. (22) Cheung ve arkadaşları sintigrafik olarak pediküllü iliak kemik greftinin olumlu sonuçlarını ortaya koyabilmişlerdir. (23) Bu tekniğin avantajları: 1) nekrozun tamamiyle ortadan kaldırılabilmesi, 2) kanlanması iyi olan iliak krestin eklem yüzeyindeki kollapsı mekanik olarak engelleyebilmesi, 3) iskemik başın sirkülasyonunun sağlanması, 4) serbest vaskülarize kemik greftlerinin kullanımında olduğu gibi mikrocerrahi teknikler ile damar anastomozuna gerek duyulmayışıdır. (24) Vaskülarize fibula grefti de femoral başın dekompresyonu ve sekestrın eksizyonu sonrası kullanılan bir greftleme yöntemi olup Urbaniak ve arkadaşları otojen iliak kemik grefti ile kombinasyonu sonrası başarılı sonuçlar bildirmişlerdir. (25)

Steinberg ve arkadaşları (15) dekompresyon ve greftlemeye ek olarak elektrik stimülasyon ile başarılı sonuçlar elde etmişlerdir. Evre II ve III lezyonlarda başarılı sonuçlar bildirilmesine karşın femoral baş destrüksiyonunun önlenebilmesi açısından bu tedavi şekli tek başına dekompresyon ve greftlemeye göre üstün değildir. (26)

Genç hastalarda dekompresyon ve greftleme dışında femur başını korumaya yönelik çeşitli osteotomi teknikleri bildirilmiştir. Subkondral rezorpsiyonun tamir şansını azalttığı evre III ve ileri patolojilerde kollapsı önlemek, femur başına gelen yüklerin yönünü değiştirmek sayesinde mümkün olabilir. Bu çerçevede varus osteotomileri uygulanmıştır. Femur başı lateralinde sağlam kemik olması gereklidir. Bazı yazarlar lateralde 1/3 kısmın, bazıları ise 20 derecelik ark boyunca sağlıklı kemiğe gereksinim olduğunu bildirmişlerdir. $(27,28)$ Nekroz 200 dereceden az, primer anterolateral tutulum ve genç aktif hasta söz konusuysa, valgus/fleksiyon osteotomi yapılabilir. Daha santral yerleşimli bir lezyon varsa, bu durumda da varus veya varus/ekstansiyon osteotomi uygulanabilir. (29) Sugioka ise yük taşıyan bölgedeki stres dağılımını azaltmaya yönelik teknik olarak oldukça güç ve popülarize olmamış kendi tekniğini önermiştir. Bu teknikte femur başı ve boynu, boynun uzun aksı boyunca 60 derece ve daha fazla döndürülmektedir. (30)

Femur başında kollaps ve asetabulumda dejeneratif değişiklikler oluştuktan sonra rekonstrüktif cerrahi girişimler tercih edilir. Bu amaçla kap artroplastisi, femur başı replasmanı, eklem yüzeylerinin değiştirilerek femur başı ve boynunun korunduğu cerrahi tek- 
nikler uygulanmış olsa da artık geçerliliği kalmamış tekniklerdir. Günümüzde evre IV gibi avasküler nekroz neticesinde asetabulumda dejeneratif değişikliklerin olduğu olgularda genç hastalarda artroplasti düşünülebilmektedir. Artroplasti düşünülen hastalarda kemik büyümesine olanak sağlayan çimentosuz pro- tezler ve debris açısından daha avantajı ılan yüzeylerin kullanıldığı dizaynlar tercih edilmektedir. (31) Tedavi amacı ile ileri evrelerde kullanılmıs ancak artık terk edilmiş diğer cerrahi teknikler de kalça füzyonu ve Girdlestone psödoartrozdur (rezeksiyon artroplastisi).

\section{KAYNAKLAR}

1. Russel I. An essay on necrosis. Sectionl. General remarks and description of appaerences. Clin Orthop1978; 130: 5.

2. Phemister DB. Treatment of the necrotic head of the femur in adults. J Bone Joint Surg 1947; 31A: 55.

3. Spence RK, Alave A, Barker CF ve ark. Osteonecrosis in renal transplant recipient-a prospective study. In: Arlet J, Ficat RP, Hungerford DS eds. Bone Circulation. Baltimore: Williams \& Wilkins, 1984: 246

4. Basset GS, Apel DM, Wintersteen VG, Tolo VT. Measurement of femoral head microcirculation by laser Doppler flowmetry. J Pediatr Orthop 1991;11: 307-13.

5. Ficat RP. Idiopathic bone necrosis of the femoral head: early diagnosis and treatment. J Bone Joint Surg 1985; 67B: 3-9.

6. Plancher KD, Razi A. Management of osteonecrosis of the femoral head. Orthop Clin North Am 1997; 28(3): 461-75.

7. Hastings DE, Macnab I. Spontaneous avascular necrosis of the femoral head. Can J Surg 1965; 8: 68 .

8. Hungerford DS, Lennox DW. The importance of increased intraosseous pressure in the development of osteonecrosis of the femoral head. Implications of treatment. Orthop Clin North Am 1985; 16: 635.

9. Ficat RP, Arlet J: Ischemia and Necrosis of Bone. Baltimore, Williams \& Wilkins, 1980.

10. Steinberg ME, Brighton CT, Corres A ve ark. Osteonecrosis of the femoral head: Results of core decompression and grafting with and without electrical stimulation. Clin Orthop 1989; 249: 199 .

11. Marcus ND, Enneking WF, Massam RA. The silent hip in idiopathic aseptic necrosis: Treatment by bone grafting. J Bone Joint Surg 1973; 55A: 1351.

12. Hungerford DS, Zizic TM. Alcoholism associated ischemic necrosis of the femoral head: Early diagnosis and treatment. Clin Orthop 1978; 130: 144.

13. Woodhouse CF. Tetracycline vascular maps of the femoral head. J Bone Joint Surg 1962; 44A: 1029.

14. Musso ES, Mitchell SN, Schink-Asani M ve ark. Results of conservative management of osteonecrosis of the femoral head: A retrospective review. Clin Orthop1986; 207: 209 .

15. Steinberg ME, Hayken GD, Steinberg DR. A quantitative system for staging avascular necrosis. J Bone Joint Surg 1995; 77B: 34 .
16. Koo KH, Kim R, Ko GH, Song HR, Yeong ST, Cho SH. Preventing collapse in early osteonecrosis of the femoral head. A randomized clinical trial of core decompression. J Bone Joint Surg. 1995; 77 (B): 870-4.

17. Markel DC, Miskovsky C, Sculco TP, Pellicci PM, Salvati EA. Core decompression for osteonecrosis of the femoral head. Clin Orthop 1996; 323: 226-33.

18. Meyers $\mathrm{MH}$. Osteonecrosis of the femoral head treated with muscle-pedicle graft. Orthop Clin North Am 1985; 16 : 741-45.

19. Disulescu I. Aseptic necrosis of the femoral head and its treatment. In: Casteleyn PP, Duparc J, Fulford P, eds. European Instructional Course Lectures Vol: 2. London: The British Editorial Society of Bone and Joint Surgery, 1995: 9-18.

20. Meyers MH. Resurfacing of the femoral head with fresh osteochondral allografts. Clin Orthop 1985; 197: 111.

21. Malizos KN, Seaber AV, Glisson RR, Quarles LD, Rizk WS, Urbaniak JR. The potential of vascularized cortical graft in revitalizing necrotic cancellous bone in canines. Osteonecrosis: Etiology, Diagnosis and Treatment. American Academy of Orthopaedic Surgeons 1997; 361-2.

22. Rosenwasser MP, Garine JP, Kiernan HA, Michelsen CB. Long term follow-up of thorough debridement and cancellous bone grafting of the femoral head for avascular necrosis. Clin Orthop 1994; 306: 17-27.

23. Cheung HS, Stewart IE, Ho KL, Leung PC, Metneweli C. Vascularised iliac crest grafts. Evaluation of viability status with marrow scintigraphy. Radiology 1993; 186(1): $241-5$.

24. Chen ZW, Zhang GJ, Qiu HB. Vascularized pedicle iliac crest graft as treatment for aseptic necrosis of femoral head. In: Urbaniak JR ed. Microsurgery For Major Limb Reconstruction. St. Louis: C.V. Mosby Company, 1987: 185-8.

25. Urbaniak JR, Coogan PG, Gunneson EB ve ark. Treatment of osteonecrosis of the femoral head with free vascularized fibular grafting. J Bone Joint Surg 1995; 77A: 681.

26. Trancik T, Lunceford E, Strum D. The effect of electrical stimulation on osteonecrosis of the femoral head. Clin Orthop 1990; 256: 120. 
27. Kerboul M, Thomine J, Posstel M, et al. The conservative surgical treatment of idiopathic aseptic necrosis of the femoral head. J Bone Joint Surg 1974; 56B: 291.

28. Saito S, Ohzono K, Ono K. Joint preserving operations for idiopathic avascular necrosis of the femoral head: Results of the core decompression, grafting, and osteotomy. J Bone Joint Surg 1988; 70B: 78.

29. Wagner $H$, Baucher W. Five year follow-up of intertrochanteric ostoetomy for ischemic necrosis of the femoral head. Poceedings of the Symposium on Osteotomy of the Hip and Knee. Boston: 1986.
30. Sugioka Y. Transtrohanteric rotational osteotomy in the treatment of idiopathic and steroid induced femoral head necrosis, Perthes disease, slipped capital femoral epiphysis, and osteoarthritis of the hip. Clin Orthop 1984; 184: 12.

31. Philips FM, Pottenger LA, Finn HA ve ark. Cementless total hip arthroplasty in patients with steroid-induced avascular necrosis of the hip. Clin Orthop 1994; 303: 147. 